\title{
Solução concentrada de albumina eqüina na fluidoterapia em eqüinos com desidratação leve a moderada
}

[Equine concentrated albumin solution in the fluid therapy in horses with slight to moderate dehydration]

\author{
C.B. Belli ${ }^{1}$, L.E.S. Michima ${ }^{1}$, S.M. Latorre ${ }^{1}$, W.R. Fernandes ${ }^{2}$ \\ ${ }^{1}$ Aluno de pós-graduação - FMVZ-USP - São Paulo, SP \\ ${ }^{2}$ Faculdade de Medicina Veterinária e Zootecnia - USP - São Paulo, SP
}

\begin{abstract}
RESUMO
Avaliou-se o efeito da solução concentrada de albumina eqüina diluída a 5\% em solução fisiológica (SF) durante fluidoterapia em eqüinos, após indução de desidratação leve a moderada, utilizando-se cinco eqüinos adultos, sem alterações clínicas. Cada animal passou por dois protocolos de fluidoterapia: apenas com SF (metade sob pressão e metade em fluxo contínuo - grupo-controle); com solução de albumina eqüina e SF (apenas em fluxo contínuo - grupo experimental). Avaliaram-se peso, exame físico geral, hematócrito, osmolalidade plasmática, gasometria, proteína total, albumina, uréia, creatinina, $\mathrm{Na}, \mathrm{K}$, débito cardíaco e pressão arterial, e calcularam-se pressão oncótica e volume plasmático. Após a aplicação de metade da SF sob pressão nos animais do grupo-controle, as alterações no hematócrito, na proteína total, na albumina, na pressão arterial e na pressão oncótica foram semelhantes às encontradas nos do grupo experimental após aplicação apenas da solução de albumina. Conclui-se que a solução de albumina eqüina é de fácil preparação e aplicação, não demonstra efeitos deletérios na dose e velocidade utilizadas e é passível de ser utilizada como colóide na fluidoterapia na espécie eqüina.
\end{abstract}

Palavras-chave: eqüino, albumina, fluidoterapia

\begin{abstract}
The effect of the equine concentrated albumin solution diluted to $5 \%$ in physiologic saline solution (PSS) during fluid therapy in horses after induced slight to moderate dehydration was evaluated in five adult horses with no clinical alterations. Each animal was submitted to two fluid therapy protocols; with only PSS (half of the total volume under pressure and half in continuous flow - control-group), or with equine albumin solution and PSS (only in continuous flow - treated-group). Body weight; general physical examination, packed cell volume (PCV); plasmatic osmometry; gasometry, total protein, albumin, urea, creatinin, $\mathrm{Na}$, and $\mathrm{K}$, cardiac output; and arterial pressure; and calculation of the oncotic pressure and plasmatic volume were evaluated. After the administration of the first half of PSS under pressure in control group, it was observed that alterations in PCV, total protein, albumin, arterial pressure, and oncotic pressure were similar to those found in experimental group after the administration of the albumin solution. It was concluded that the equine albumin solution is easily prepared and administered, with no deleterial effects in the employed dose and speed, and it is suitable for use as a colloid in fluid therapy in equine species.
\end{abstract}

Keywords: equine, albumin, fluid therapy

Recebido em 20 de junho de 2007

Aceito em 14 de dezembro de 2007

Endereço para correspondência (corresponding address)

Rua Almeida Maia, 38/62 - 02338-060 - São Paulo, SP

E-mail:cbbelli@usp.br 


\section{INTRODUÇÃO}

A desidratação é um problema comum em várias situações e doenças (Spier et al., 1993) e a fluidoterapia é utilizada durante o tratamento de várias enfermidades em eqüinos (Freestone, 1993).

Os fluidos disponíveis para utilização em humanos e animais são classificados em cristalóides (soluções contendo água, eletrólitos e/ou açúcares) e colóides. Há os colóides naturais (sangue, plasma, albumina e fração protéica plasmática) e os sintéticos - hetastarch, dextran, gelatina e hemoglobina polimerizada (Roberts e Bratton, 1998).

Os colóides exercem função semelhante a das proteínas plasmáticas, pois suas grandes moléculas permanecem dentro dos vasos sangüíneos, aumentando a pressão oncótica, favorecendo a permanência de fluído e atraindo mais fluido do interstício (Griffel e Kaufman, 1992). Já os cristalóides permanecem apenas 30 minutos no espaço intravascular (Nadel et al., 1998), podendo não reverter quadros de insuficiência circulatória aguda e desidratação grave. Mesmo assim, os cristalóides ainda são mais utilizados na clínica eqüina, principalmente por serem mais baratos (Griffel e Kaufman, 1992).

Embora o plasma seja o colóide usado com maior freqüência em eqüinos, ele é o menos efetivo em aumentar a pressão oncótica, pela rápida redistribuição das proteínas para o espaço extravascular (Carlson, 1997). Além disso, o preço de uma plasmaterapia efetiva em eqüinos ainda é alto (Seahorn e Cornick-Seahorn, 1994). Uma alternativa é a utilização de colóides sintéticos (que podem substituir apenas temporariamente os efeitos oncóticos no volume plasmático, sem outras funções como o transporte de substâncias) ou de albumina (Griffel e Kaufman, 1992).

A albumina é responsável por $75 \%$ a $80 \%$ da pressão oncótica coloidal plasmática (Griffel e Kaufman, 1992), e seu efeito após infusão depende primariamente da quantidade fornecida e não da concentração da solução (Roberts e Bratton, 1998). Apenas 50\% do volume de solução de albumina injetado permanecem no espaço intravascular após 4 horas, com o restante sendo redistribuído para o extravascular (Swisher e Petz, 1981).

Há indicações específicas para o uso de albumina em humanos, mas seu benefício ainda é controverso na literatura. Embora alguns estudos estabeleçam uma relação inversa entre nível de albumina sérica e mortalidade ou demonstrem sua segurança (Human..., 1998; Nadel et al., 1998; Triulzi, 2003), há estudos que sugerem que sua utilização aumentaria o risco de morte em pacientes críticos (Human..., 1998). Mas, apesar da possibilidade de efeitos colaterais, o principal fator limitante ao uso de albumina em humanos é o custo (Roberts e Bratton, 1998).

Em animais, quase tudo que se sabe sobre a ação de albumina são experimentos com albumina humana em animais de laboratório (Dawidson et al., 1986), cães (Hein et al., 1988) e ovinos (Layon e Gallagher, 1990), todos eles com bons resultados.

$\mathrm{Na}$ preparação de soros específicos, antipeçonhentos ou antitóxicos, de origem eqüina, pelo Instituto Butantan, por meio de adaptação da técnica de Schneider, grandes volumes de solução de albumina são produzidos, sendo possível o aproveitamento dessa solução para utilização laboratorial ou em clínica veterinária (Marcelino e Guidolin, 1991).

Como em eqüinos não há nenhum trabalho sobre a utilização de soluções de albumina, os objetivos deste trabalho foram avaliar o uso de solução de albumina eqüina durante fluidoterapia em eqüinos após indução de desidratação leve a moderada e comparar sua ação em relação à fluidoterapia apenas com solução fisiológica.

\section{MATERIAL E MÉTODOS}

Para o desenvolvimento do trabalho, foram utilizados cinco eqüinos, três machos e duas fêmeas, sem alterações clínicas, com idades entre nove e 15 anos, e pesos entre 373 e $491 \mathrm{~kg}$. Cada animal passou pelo protocolo de dois grupos experimentais, com intervalo mínimo de sete dias entre os dois: grupo-controle (GC) fluidoterapia intravenosa com solução fisiológica (SF); grupo experimental (GE) - fluidoterapia intravenosa com solução de albumina eqüina e solução fisiológica. 
A desidratação foi induzida mediante aplicação de furosemida ( $2 \mathrm{mg} / \mathrm{kg}$, IV) ao final da tarde (T0), acompanhada por jejum hídrico. Na manhã seguinte (T1), foi feita nova aplicação de furosemida, iniciando-se a fluidoterapia apenas ao meio-dia (T2), em um total aproximado de 21 horas de indução.

O volume de solução físiológica a ser reposto foi calculado pela estimativa de desidratação (Seahorn e Cornick-Seahorn, 1994) em função do peso corporal. A solução concentrada de albumina eqüina foi fornecida pelo Instituto Butantan, refrigerada e acondicionada em bolsas plásticas, e serviu de base para a preparação de solução a 5\% em SF, diluída na hora da aplicação. A quantidade a ser aplicada foi calculada de modo que representasse $7,5 \%$ do total de albumina sérica de cada animal, com concentração final de $2,2 \%$ para a proteína total e de $1,5 \%$ para a albumina.

No GC, metade da SF foi feita sob pressão e metade em fluxo contínuo. As avaliações neste grupo foram feitas após a infusão sob pressão (T3), após metade da infusão em fluxo contínuo (T4) e ao final da infusão total (T5). No GE, primeiro foi feita a infusão da solução de albumina, de forma lenta nos primeiros 15 minutos, com a finalidade de se observar a eventual ocorrência de efeitos colaterais, e depois em fluxo contínuo, e a seguir a de SF apenas em fluxo contínuo. Neste grupo, as avaliações foram feitas ao final da infusão de albumina (T3), na metade da infusão de SF (T4) e ao final da infusão total (T5).

Avaliaram-se freqüências cardíaca e respiratória, coloração das mucosas, tempo de preenchimento capilar (TPC), temperatura, turgor de pele, movimentos do ceco, auscultação abdominal e cárdiopulmonar, peso, hematócrito, osmometria plasmática, hemogasometria, proteína total, albumina, uréia $(\mathrm{U})$, creatinina $(\mathrm{C}), \mathrm{Na}, \mathrm{K}$, débito cardíaco e pressão arterial.

A osmometria foi avaliada em microosmômetro $^{1}$. A pressão arterial foi medida de forma indireta na artéria coccígea. O débito cardíaco foi avaliado de modo não invasivo por meio do ecocardiograma no modo $\mathrm{M}$, na região paraesternal direita, com aparelho de ultra-

${ }^{1}$ Micro Osmometer 3300, Advanced $®$ - Norwood, EUA. sonografia. A pressão oncótica plasmática foi estimada pela fórmula proposta por Brown et al. (1994) para eqüinos. A porcentagem de alteração do volume plasmático foi calculada pela fórmula proposta por Carlson (1997).

Os resultados das avaliações foram comparados estatisticamente entre os tempos antes e depois da hidratação e entre os dois grupos experimentais. O turgor de pele foi analisado apenas de forma descritiva. Para as variáveis paramétricas, utilizaram-se a análise de variância e o teste de comparação múltiplo Tukey-Kramer, para comparar os tempos dentro do grupo, e o teste $\mathrm{t}$ pareado, para compar o tempo entre os grupos. Para as variáveis não paramétricas, déficit básico, uréia e débito cardíaco pelo grande desvio-padrão apresentado, utilizaram-se o teste Kruskal-Wallis e o teste de comparação múltipla Dunn para comparar tempos dentro de grupo, e o teste Wilcoxon para testes pareados para comparar o tempo entre os grupos. Utilizouse o programa de computador GrafPad InStat ${ }^{2}$, considerando-se $\quad \mathrm{P} \leq 0,05$ para indicar significância estatística.

\section{RESULTADOS E DISCUSSÃO}

Os valores das freqüências cardíaca e respiratória, mucosas, tempo de preenchimento capilar, temperatura e movimentos do ceco permaneceram dentro da normalidade, indicando que os animais não passaram por estresse excessivo ou grande alteração circulatória.

A desidratação estimada variou de $5,0 \%$ a $7,5 \%$, com média de $6,2 \pm 0,8 \%$ (GC) e de $6,7 \pm 0,6 \%$ (GE), sem diferença estatística entre os grupos.

A diluição a $5 \%$ da solução concentrada de albumina, com concentração final de albumina de $1,5 \%$, foi utilizada para evitar sobrecarga circulatória, pois com animais saudáveis, apenas com desidratação leve a moderada, não é indicada uma aplicação de colóides em excesso. Mesmo na literatura há relatos da utilização de baixas concentrações de solução de albumina $(1,25 \%)$ com diferenças evidentes em relação aos cristalóides (Denis et al., 1987).

${ }^{2}$ GraphPad InStat version 3.01 for Windows 95, GraphPad Software - San Diego, EUA. 
A preparação da solução de albumina mostrou-se simples, necessitando apenas de cuidados básicos para evitar sua contaminação e infusão lenta na solução fisiológica para evitar a formação de espuma. $\mathrm{O}$ volume infundido variou entre 3 e 4 litros, e a aplicação não produziu efeitos colaterais perceptíveis, mostrando-se segura, como na utilização em humanos (Roberts e Bratton, 1998; Triulzi, 2003), na dose e velocidade utilizadas.

O tempo total de infusão foi maior no GE $(184 \pm 48,2$ minutos no GC e $251,0 \pm 44,6$ minutos no $\mathrm{GE}$, com $\mathrm{P}=0,0333$ ), devido à diferença nos protocolos. Essa diferença não invalida a comparação, pois a idéia foi testar dois protocolos para rápida reposição de fluido infusão inicial de grande volume de cristalóide sob pressão ou infusão de colóide, seguidas de fluidoterapia em fluxo contínuo.

Embora a porcentagem de desidratação final estimada fosse estatisticamente semelhante entre os grupos, ao final da fase de infusão apenas os animais do GC voltaram a se apresentar hidratados de acordo com esse parâmetro, enquanto os do GE ainda apresentavam desidratação leve.

Tendo em vista que a recuperação de peso dos animais não apresentou diferença estatística $(98,4 \pm 0,6 \%$ no GC e $97,9 \pm 1,4 \%$ no GE, com $\mathrm{P}$ $=0,3134$ ) e que o turgor de pele avalia melhor a hidratação intracelular (Freestone, 1993), é possível afirmar que a aplicação de solução de albumina leva a maior aumento de fluido principalmente extracelular em relação à aplicação apenas de solução fisiológica. Além disso, o tempo de hidratação foi maior no GE, o que poderia representar maior tempo para a distribuição de líquido para os tecidos, mas tal fato não foi o observado.

Com relação à uréia e creatinina, não houve variação estatística significante durante o experimento, indicando que houve manutenção da função glomerular.

O sódio apresentou diferença estatística apenas no T5 entre os grupos $(136,4 \pm 8,5 \mathrm{mmol} / 1$ no GC e $134,2 \pm 7,9 \mathrm{mmol} / 1$ no $\mathrm{GE}$, com $\mathrm{P}=0,0295)$. Isso pode ter ocorrido por diferença de fluxo entre os compartimentos, visto que no GC houve maior distribuição de líquido para o intracelular que no GE. Como o sódio é predominante no extracelular, o maior aporte líquido para o intracelular pode determinar maior concentração deste no plasma do animal (Johnson, 1998).

O potássio apresentou diferença estatística apenas entre os tempos experimentais e não entre os grupos. Houve diminuição durante a indução da desidratação, explicada pela aplicação da furosemida (Carlson, 1997), sem retorno ao normal durante a hidratação pelo fato de as soluções infundidas serem livres de potássio. Como a furosemida tem ação rápida, sendo quase totalmente eliminada em quatro horas (Hinchcliff e Muir, 1991), ela não influenciou a fase de infusão do experimento, que sempre se iniciava cerca de cinco horas após a última aplicação da substância.

A osmolalidade manteve-se dentro dos parâmetros de normalidade de 270 a 300 $\mathrm{mOsm} / \mathrm{kg}$ (Carlson, 1997) e sem diferença estatística significativa em nenhum momento do experimento, nos dois grupos. O não aumento com a desidratação pode ser explicado pela mobilização de líquido extravascular, e a não diminuição com a fluidoterapia provavelmente ocorreu em razão da utilização de fluidos com eletrólitos.

Em relação à pressão oncótica, esperava-se uma alteração com a infusão de solução de albumina. No entanto, a pressão diminuiu de forma significativa após o início da fluidoterapia, tanto no grupo-controle $(25,34 \pm 1,9 \mathrm{mmHg}$ no $\mathrm{T} 2$ para $19,29 \pm 1,3 \mathrm{mmHg}$ no $\mathrm{T} 3$, com $\mathrm{P}<0,0001)$ quanto no experimental $(25,74 \pm 2,3 \mathrm{mmHg}$ no $\mathrm{T} 2$ para $20,58 \pm 4,3 \mathrm{mmHg}$ no $\mathrm{T} 3$, com $\mathrm{P}=0,0020$ ).

A pressão oncótica calculada não é tão precisa quanto a medida diretamente. Mesmo assim, ela mostra, mais que um valor fixo, a tendência durante a hidratação. Sua diminuição no T3 do GE mostra claramente a atração de fluido intersticial para o intravascular. Não há outra explicação para essa diminuição da pressão oncótica do GE visto que, no T3, os animais haviam recebido apenas três a quatro litros da solução de albumina, enquanto os do GC, na mesma fase, já haviam recebido infusão sob pressão de 9 a 15 litros. 
Isso também é visto em humanos, nos quais, logo após a aplicação de colóides, há aumento transitório da pressão oncótica, seguido de aumento do volume sangüíneo e pressão venosa central pela atração de líquidos ao intravascular, diminuindo novamente a pressão oncótica. Esse rápido equilíbrio faz com que a mudança na pressão oncótica após aplicação de cristalóides e colóides seja pequena (Shippy e Shoemaker, 1983).

Durante a hidratação, os dois grupos apresentaram diminuição dos valores de hematócrito, mais prontamente no GC que no GE $(26,6 \pm 2,6 \%$ e $32,0 \pm 2,9 \%$ respectivamente, no $\mathrm{T} 3$, com $\mathrm{P}=0,0197$ ), pelos motivos já citados anteriormente de diferença de volume infundido no T3.

No T3, a alteração do volume plasmático em relação ao volume inicial $(100,0 \%)$ também se mostrou estatisticamente maior no GC $(167,3 \pm 25,1 \%$ contra $114,7 \pm 17,1 \%$ no GE, com $\mathrm{P}=0,0006)$. Embora tenha sido calculado e, por isso, não seja preciso, indica apenas que os animais do GC receberam maior volume de fluido, com maior redução do hematócrito, usado para este cálculo. Este achado é compatível com a ação coloidal da albumina, pois, se foi infundido menor volume, alterando menos o hematócrito, a pressão oncótica só poderia se apresentar menor por atração de fluido para o intravascular.

Os valores da gasometria apresentaram-se dentro da normalidade, apenas com leve alcalose metabólica (maior $\mathrm{pH}, \mathrm{BE}$ e bicarbonato) durante a fase de desidratação pela ação da furosemida (Hinchcliff e Muir, 1991). Após a fluidoterapia, os valores de $\mathrm{pH}$ voltaram ao normal. Em nenhum momento, houve mudança compatível com alteração respiratória, citada na literatura como uma das possíveis complicações do uso de soluções de albumina em humanos (Griffel e Kaufman, 1992; Roberts e Bratton, 1998; Triulzi, 2003).

Com relação à proteína total e albumina séricas, as alterações acompanharam o esperado: aumento com a desidratação e diminuição com a hidratação. Na comparação dos grupos, houve diferença estatística apenas com a albumina no T4 $(2,72 \pm 0,22 \mathrm{~g} / \mathrm{dl}$ no GC e $2,83 \pm 0,20 \mathrm{~g} / \mathrm{dl}$ no GE, com $\mathrm{P}=0,0341$ ), explicada pela própria infusão de albumina, embora essa tendência possa ser observada também nos outros tempos, sem diferenças estatística (Fig. 1). Outro aspecto interessante é que a albumina no T3 $(2,68 \pm 0,16 \mathrm{~g} / \mathrm{dl}$ no $\mathrm{GC}$ e $2,92 \pm 0,50 \mathrm{~g} / \mathrm{dl}$ no $\mathrm{GE})$ em relação a do $\mathrm{T} 2(3,42 \pm 0,17 \mathrm{~g} / \mathrm{d} l$ no $\mathrm{GC}$ e $3,45 \pm 0,21 \mathrm{~g} / \mathrm{dl}$ no GE) apresentou diminuição significativa $(\mathrm{P}<0,0001$ para o $\mathrm{GC}$ e $\mathrm{P}=0,0023$ para o GE) nos dois grupos, mas não entre os grupos, evidenciando novamente a ação oncótica da albumina.

Neste experimento, os resultados da mediana do débito cardíaco, em 1/min., para o GC foram 15,20 (T0), 10,50 (T2) e 13,80 (T5) e para o GE foram 17,35 (T0), 11,25 (T2) e 14,00 (T5), sem diferença estatística entre eles.

Os valores de pressão arterial (média, sistólica e diastólica), mesmo com as alterações no volume circulante (Carlson, 1997), não apresentaram diferença estatística entre os grupos. A não diferença estatística da pressão arterial média (Fig. 2) entre os grupos no T3 $(10,7 \pm 2,0 \mathrm{mmHg}$ no GC e $11,7 \pm 2,0 \mathrm{mmHg}$ no $\mathrm{GE}$ ) é a observação mais importante pela diferença de volume recebido pelos dois grupos neste tempo experimental. Com apenas poucos litros de solução de albumina, o aumento de pressão arterial foi equivalente ao encontrado nos animais do $\mathrm{GC}$, que já haviam recebido metade do volume calculado para a hidratação, indicando a atração de fluido para o intravascular no GE.

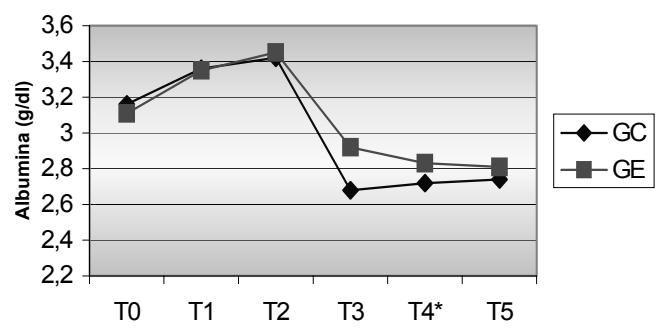

Figura 1. Valores de albumina sérica de eqüinos dos grupos controle (GC) e experimental (GE) em todos os tempos (T0 a T5).

As diferenças foram observadas principalmente no T3. No GC, que havia recebido metade do volume calculado de SF sob pressão, eram esperadas as alterações na pressão arterial, hematócrito, proteína total, albumina e pressão 
oncótica. Mas a ocorrência de alterações equivalentes no GE, que recebera apenas poucos litros de albumina, indica atração de fluido para o intravascular pela ação oncótica da albumina. Permite, ainda, constatar a manutenção do fluido neste local, já que, ao final da infusão, o GE apresentava maior turgor de pele em relação ao GC.

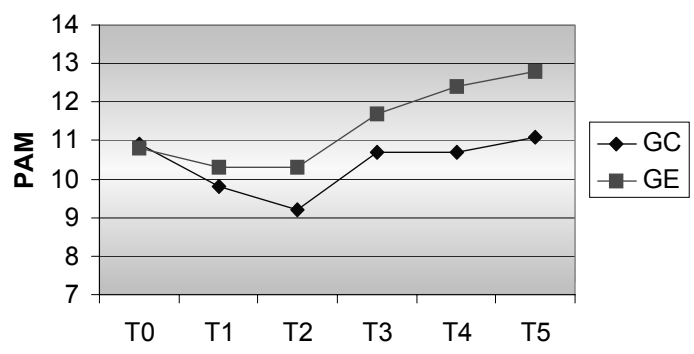

Figura 2. Pressão arterial média (PAM) de eqüinos dos grupos controle (GC) e experimental (GE) em todos os tempos do experimento (T0 a T5).

A aplicação de pequeno volume de solução de albumina foi capaz de causar efeitos comparáveis aos da infusão sob pressão de metade do volume de solução fisiológica calculado para hidratar cada animal. Visto que os colóides têm grande aplicabilidade na clínica eqüina e que a obtenção de plasma nem sempre é fácil e barata, embora ainda haja muito que pesquisar, o uso da albumina eqüina poderá se tornar uma opção, principalmente em casos de desidratação associada à hipoalbuminemia, como na enterite anterior e na colite (Freestone, 1993; Spier et al., 1993), e de choque hipovolêmico.

Conclui-se que a solução de albumina eqüina é de fácil preparação e aplicação, não demonstra efeitos deletérios na dose e velocidade utilizadas e é passível de ser utilizada como colóide na fluidoterapia na espécie eqüina.

\section{AGRADECIMENTOS}

Ao Instituto Butantan, pelo apoio e fornecimento da solução de albumina eqüina.

\section{REFERÊNCIAS BIBLIOGRÁFICAS}

BROWN, S.A.; DUSZA, K.; BOEHMER, J. Comparison of mesured and calculated values for colloid osmotic pressure in hospitalized animals. Am. J. Vet. Res., v.55, p.910-915, 1994.
CARLSON, G.P. Fluid, electrolyte, and acid-base balance. In: KANEKO, J.J.; HARVEY, J.W.; BRUSS, M.L. (Eds). Clinical biochemistry of domestic animals. 5.ed. San Diego: Academic, 1997. p.485-516.

DAWIDSON, I.; OTTOSSON, J.; REISCH, J.S. Infusion volumes of Ringer's lactate and 3\% albumin solution as they relate to survival after resuscitation of a lethal intestinal ischemic shock. Circul. Shock, v.18, p.277-288, 1986.

DENIS, R.; SMITH, R.W.; GRABOW, D. et al. Relocation of nonalbumin proteins after albumin resuscitation. J. Surg. Res., v.43, p.413-419, 1987.

FREESTONE, J. Fluid therapy: an integral part of treating common equine disorders. Vet. Med., v.88, p.563-570, 1993.

GRIFFEL, M.I.; KAUFMAN, B.S. Pharmacology of colloids and crystalloids. Crit. Care Clin., v.8, p.235-253, 1992.

HEIN, L.G.; ALBRECHT, M.; DWORSCHAK, M. et al. Long-term observation following traumatic-hemorrhagic shock in the dog. Circ. Shock, v.26, p.353-364, 1988.

HINCHCLIFF, K.W.; MUIR, W.W. Pharmacology of furosemide in the horse: a review. J. Vet. Intern. Med., v.5, p.211-218, 1991.

HUMAN albumin administration in critically ill patients: systematic review of randomised controlled trials. Br. Med. J., v.317, p.235-240, 1998.

JOHNSON, P.J. Physiology of body fluids in the horse. Vet. Clin. N. Am.: Equine Pract., v.14, p.1-22, 1998.

LAYON, A.J.; GALLAGHER, T.J. Five percents human albumin in lactated Ringer's solution for resuscitation from hemorrhagic shock: efficacy and cardiopulmonary consequences. Crit. Care Med., v.18, p.410-413, 1990.

MARCELINO, J.R.; GUIDOLIN, R. Preparação de soro albumina eqüina por fracionamento sulfato de amônio-etanolcalor. Bol. Biotecnol., v.2, p.15-17, 1991.

NADEL, S.; DE MUNTER, C.; BRITTO, J. et al. Albumin: saint or sinner? Arch. Dis. Child., v.79, p.384-385, 1998.

ROBERTS, J.S.; BRATTON, S.L. Colloid volume expanders. Drugs, v.55, p.621-630, 1998.

SEAHORN, T.L.; CORNICK-SEAHORN, J. Fluid therapy. Vet. Clin. N. Am.: Equine Pract., v.10, p.517-525, 1994.

SHIPPY, C.R.; SHOEMAKER, W.C. Hemodynamic and colloid osmotic pressure alterations in the surgical patient. Crit. Care Med., v.11, p.191-195, 1983.

SPIER, S.J.; SNYDER, J.R.; MURRAY, M.J. Terapia por líquidos e eletrólitos para os distúrbios gastrintestinais. In: SMITH, B.P. (Ed). Tratado de medicina interna de grandes animais. São Paulo: Manole, 1993. p.712-719.

SWISHER, S.N.; PETZ, L.D. Clinical use of blood substitutes. In: PETZ, L.D.; SWISHER, S.N. (Eds). Clinical practice of blood transfusion. New York: Churchill Livingstone, 1981. p.735-756.

TRIULZI, D. Derivados de plasma. In: Terapêtica transfusional: manual para médicos. 7.ed. São Paulo: Associação Americana de Bancos de Sangue, 2003. p.31-49. 